\title{
EDITORIAL
}

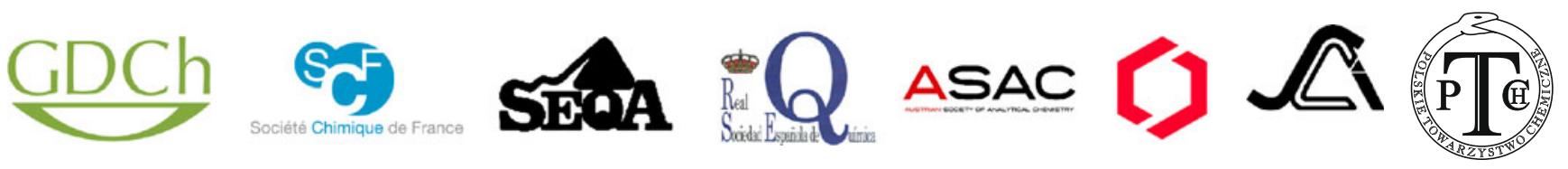

\section{Ten years of Analytical and Bioanalytical Chemistry}

Published online: 26 November 2011

(C) Springer-Verlag 2011

Ten years ago, Springer Verlag published the first issue of Analytical and Bioanalytical Chemistry. However, $A B C$, as it is commonly abbreviated to, was not a completely new journal. Rather, its history goes back to December 1861, when the first issue of Zeitschrift für Analytische Chemie was published, which, as Fresenius' Journal of Analytical Chemistry, was later merged into $A B C$. Hence, we are celebrating not only 10 years of $A B C$, but at the same time also the 150th birthday of its origin! But $A B C$ is not only a young journal with a long and great history, it is also special in another dimension, namely, its strong roots in the analytical chemistry community.

A number of European and Asian chemical societies as well as the Division of Analytical Chemistry of the European Association for Chemical and Molecular Sciences (EuCheMS) are among the official supporters of the journal. But even more importantly, the journal initiated by Germany and France is now co-owned by six more European chemical societies from Austria, Italy, Poland, Spain and Switzerland. All of these societies are directly responsible for the success of $A B C$. Many of the authors, readers and referees of $A B C$ are members of our societies and so the journal is truly a journal from the community for the community. The owner societies meet annually with $A B C$ 's editorial team from Springer
Verlag, give advice on all aspects of the journal and are involved in the selection of the editors and the International Advisory Board. As learned societies for which the dissemination of scientific knowledge is among their statutory goals, the owner societies are committed to quality and to scientific excellence as the prime feature of their journal. Right from the beginning, a major goal of the journal was to extend its scope by including life sciences, as documented by the word "bioanalytical" in the title. No doubt, the community and the International Advisory Board will make further proposals to broaden the scope of the journal owing to the important role that analytical chemistry plays in addressing global challenges.

This close interaction between the publisher and the owner societies is certainly one of the main pillars of the impressive success that has characterized $A B C$ during the past decade. With a rapidly growing Journal Impact Factor, currently of 3.841, $A B C$ is among the top journals in the field of analytical chemistry. As owner societies, we are happy about and proud of this success and we will continue to work hard so that in its second decade $A B C$ will be the first choice for submitting your best papers in analytical and bioanalytical chemistry.

Wolfram Koch, on behalf of the owner societies
Wolfram Koch

Executive Director

Gesellschaft Deutscher Chemiker (German Chemical Society)

Varrentrappstr. 40-42

60486 Frankfurt am Main

Email: w.koch@gdch.de 